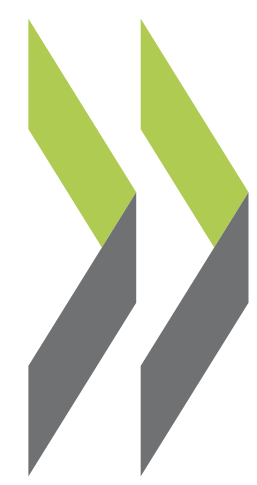

CELE Exchange, Centre for Effective Learning Environments 2009/03

\title{
An Australian Approach to School Design
}




\section{An Australian Approach to School Design}

\section{By Leigh Robinson, Taylor Robinson, Australia}

Designing a successful educational facility is predicated on ensuring the project is thoroughly understood during the critical briefing and design phases. A selection of contemporary school buildings in Perth illustrate exemplary designs.

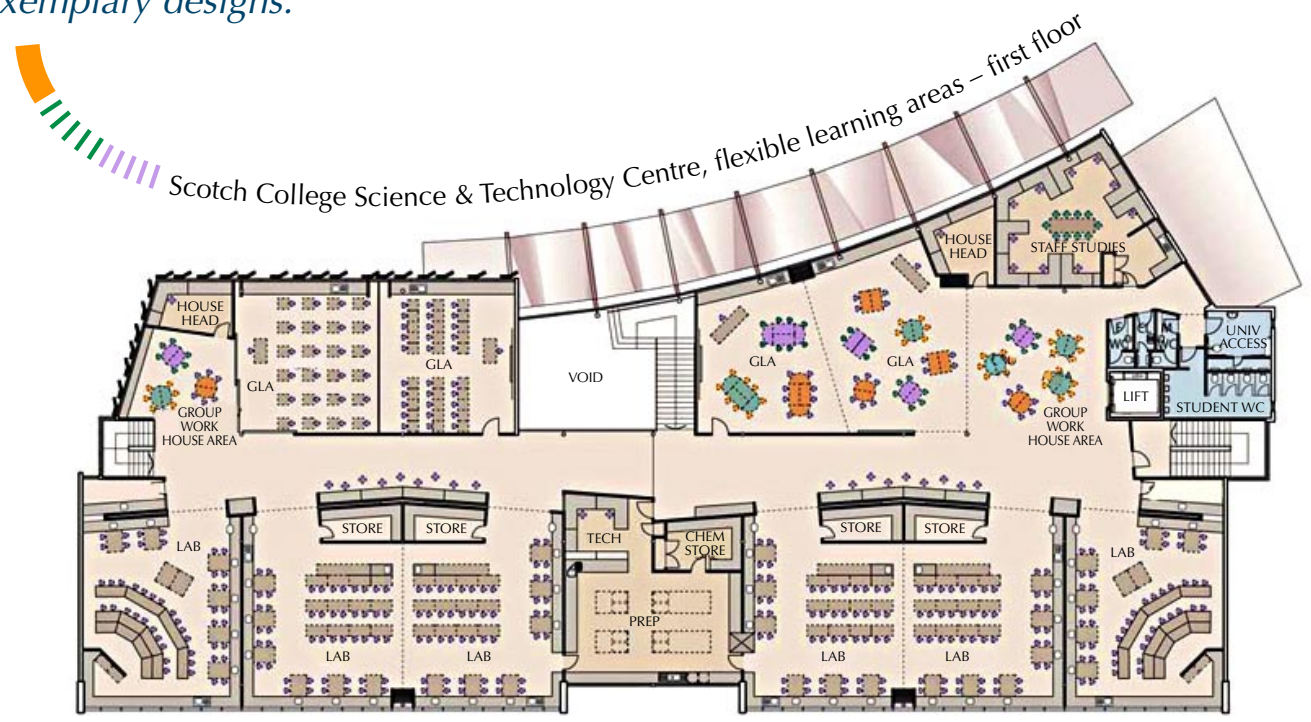

\section{INTRODUCTION}

Contemporary education design strongly emphasises stimulating, adaptable learning environments, with spaces able to support various styles of teaching and learning. Delivering successful school buildings requires a close collaborative relationship between the architect and all key stakeholders from initial briefing through to project handover.
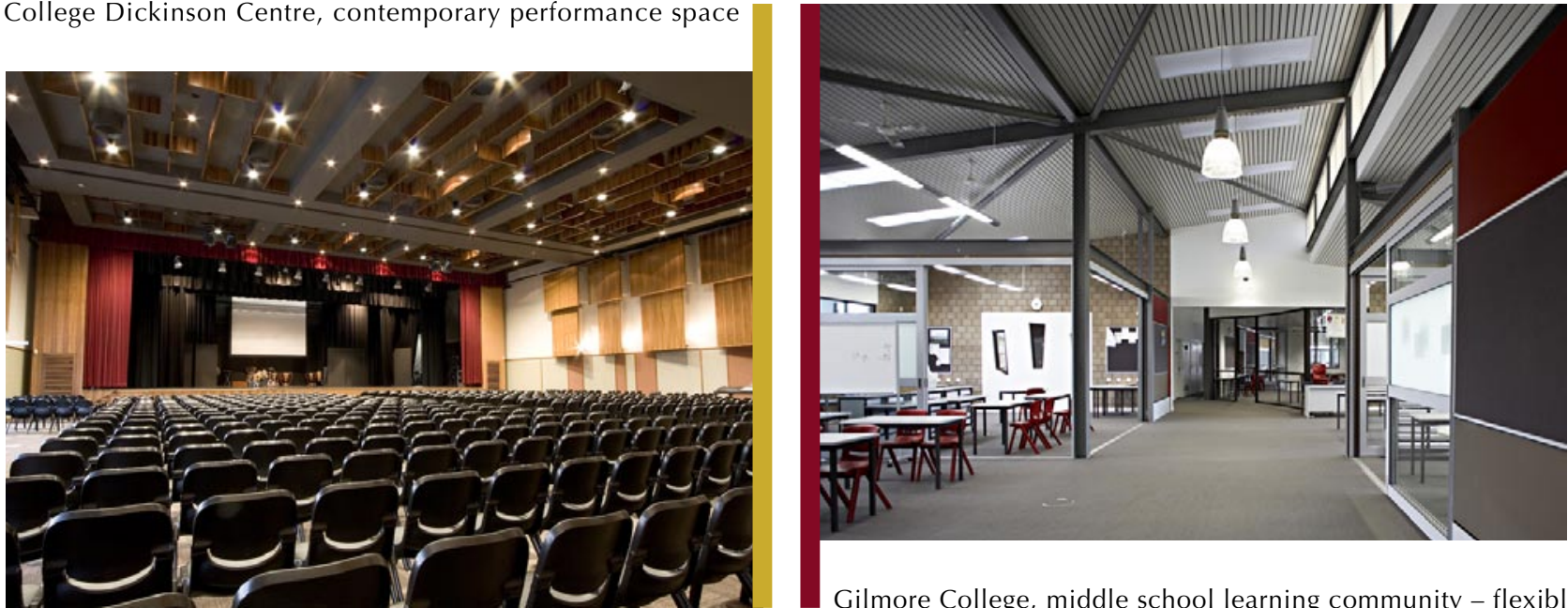

Gilmore College, middle school learning community - flexible spaces 
The brief should identify the opportunities and challenges to create an exciting architectural solution which is functional, aspirational and contextually responsible.

The design should demonstrate adaptability and flexibility, maintainability, attention to siting, a culture of community, and sustainability.

The building programme and budget also require special attention.

The photographs throughout this article show a variety of examples of educational facilities in Perth, Australia, across both the primary and secondary levels. They demonstrate the role architecture can play in creating stimulating learning environments and communities of excellence.

\section{THE BRIEF}

Firstly, exploring and developing a comprehensive brief includes both functional requirements and aspirational goals. Functional and technical expectations can be clearly briefed, however the aspirational and inspirational aspects of the brief require a commitment from all stakeholders - the school, the parent body, other users and the consultant team - to explore and expand the boundaries.

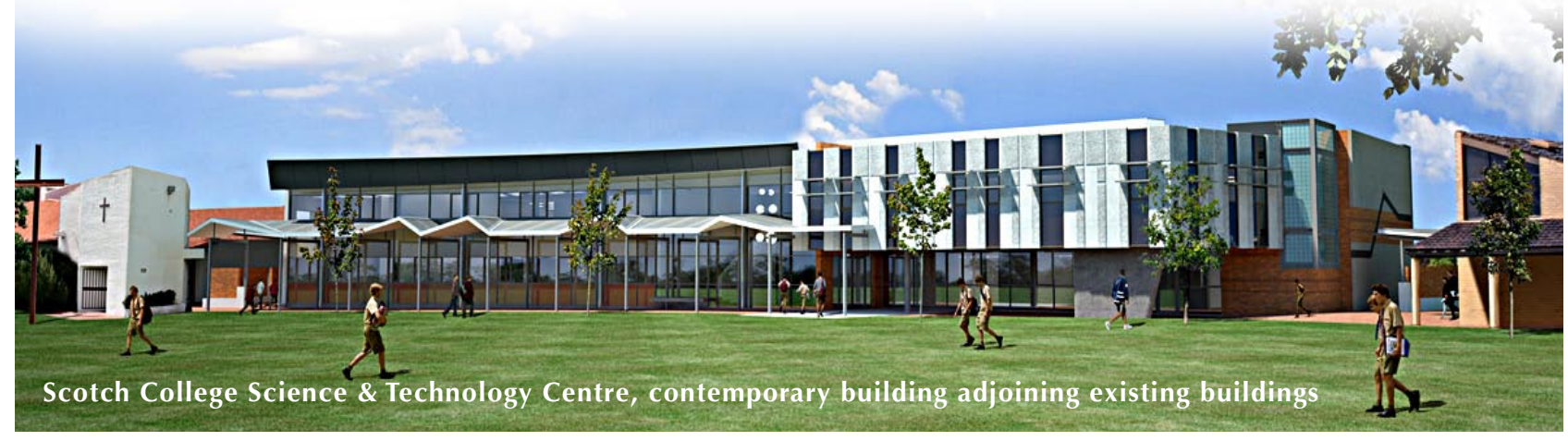

Secondly, every aspect of the project - the facilities, the planning, the building form and structure, finishes, embedded technology, adaptability and flexibility, siting, and sustainability - needs to contribute to the effectiveness of the buildings in supporting, enhancing and contributing to the whole school environment.

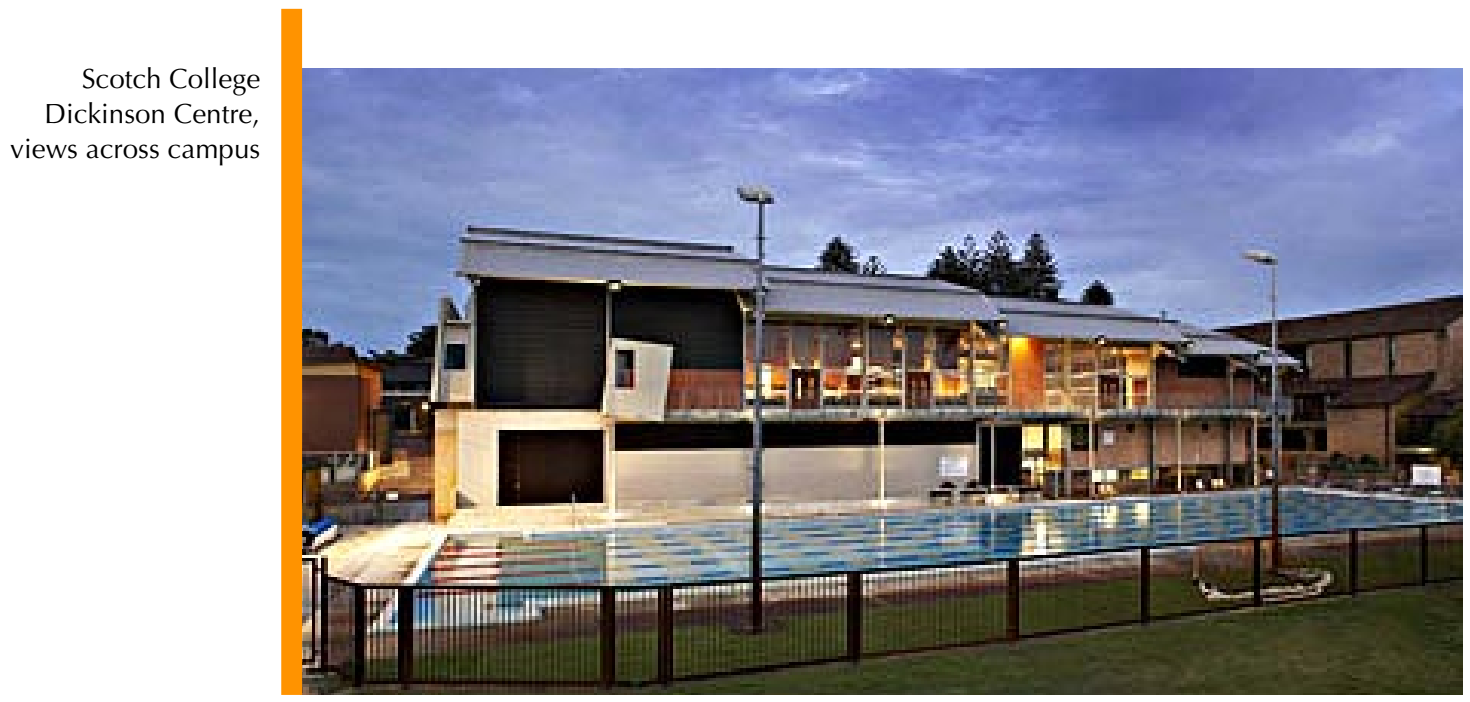




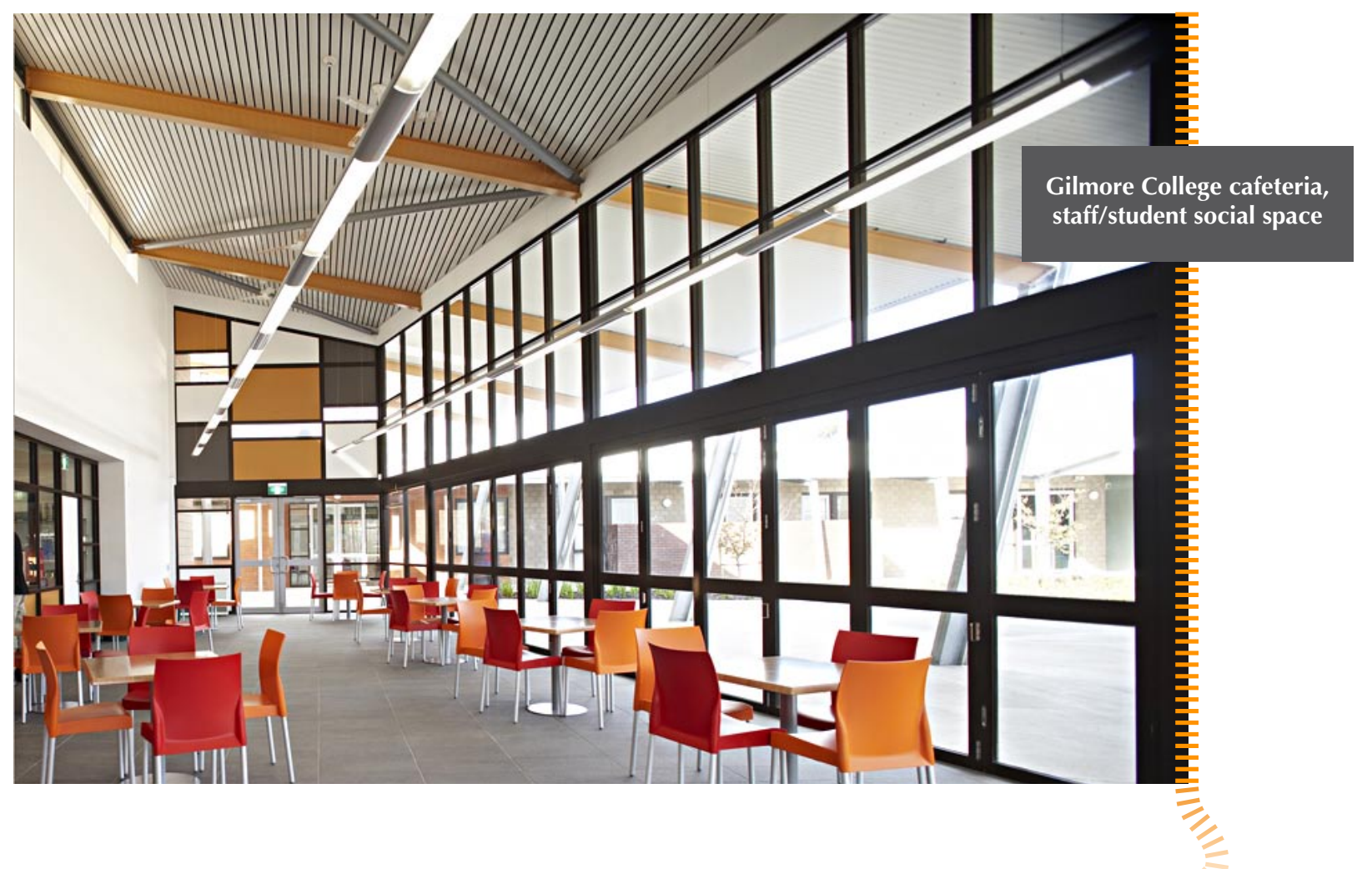

THE DESIGN

\section{Adaptability and flexibility}

Building requirements are constantly evolving and if a building is to meet the aspirations set down, it must be adaptable and flexible and allow for changes both to technology and to the demands and requirements of its user groups and the community in general.

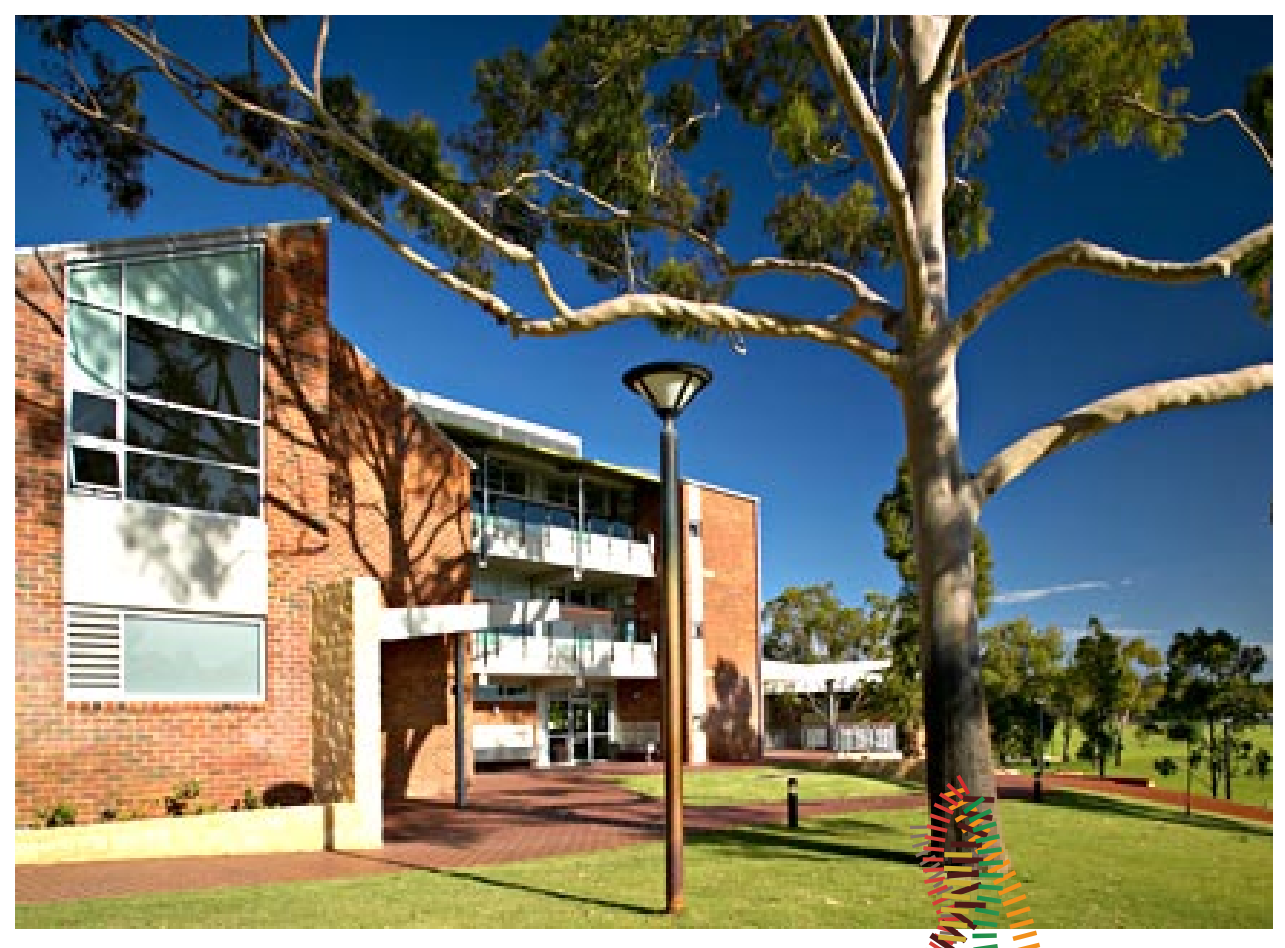

college Upper Primary, boarding house recycled into contemporary learning environment

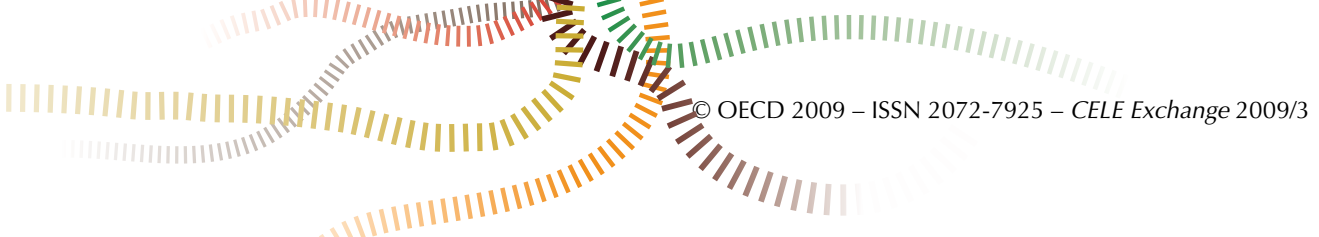



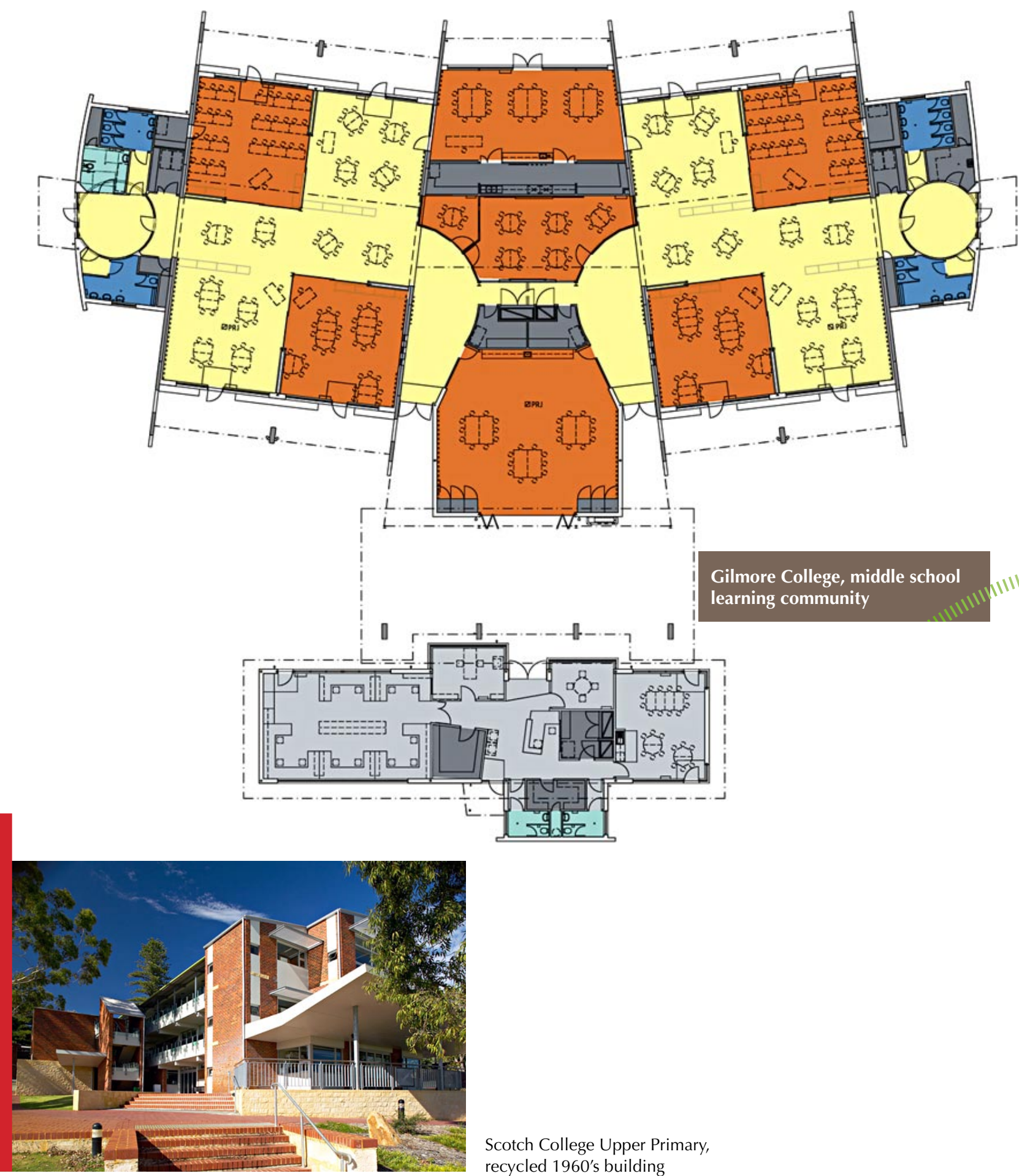

Scotch College Upper Primary, recycled 1960's building

\section{Sustainability}

A major consideration in today's energy conscious world is the design of a facility which is environmentally responsible. The facility should demonstrate a commitment to innovation and use passive design elements and active systems, materials, finishes and selections with the ultimate goal of eliminating any footprint on the environment. The refurbishment of existing buildings after they are no longer able to meet the needs of a modern curriculum is often a commercially and environmentally viable option for school decision makers. 


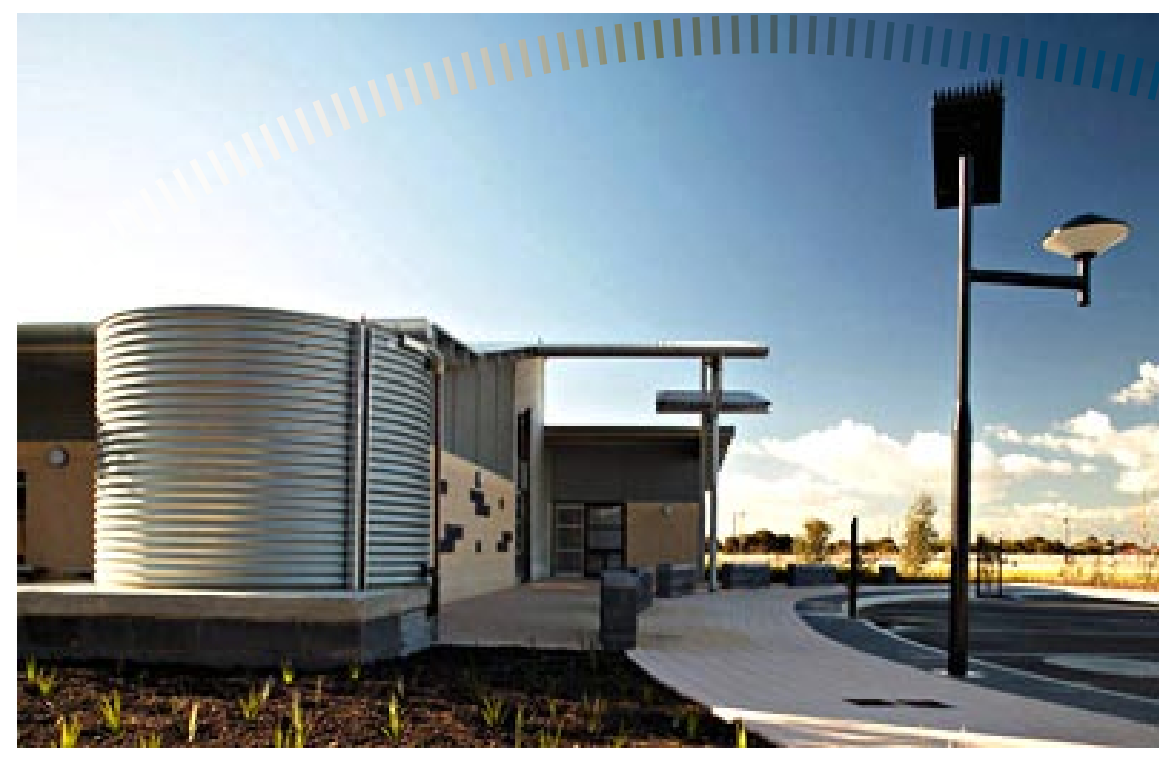

Harmony Primary School,

environmentally sustainable initiatives

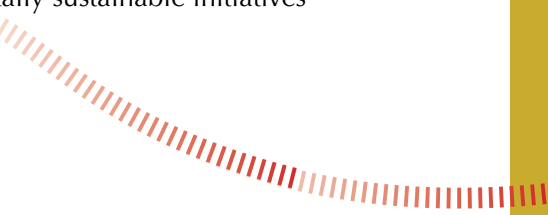

\section{PROGRAMME}

It is necessary to establish and maintain a programme for the procurement of any new facility, beginning immediately with milestones agreed with the school and key stakeholders.

In existing schools, it is important to determine the impact of a major building programme on the school's operation during the construction phase. Construction is disruptive and places stresses on staff and students. These questions should be considered: Will additional teaching spaces be required as an interim solution? Will building noise compromise student learning?

Will external breakout spaces be compromised during the construction phase?

\section{BUDGET}

One of the most significant factors in the successful delivery of any project is the building budget. Regular review is essential to ensure that the brief and the design match the budget.

A process to prioritise "must have", "nice to have" and "out of the question" should happen early in the design phase and be costed accordingly.

Costs should be kept under review by quantity surveyors when the brief is agreed, when schematic designs are prepared and during design development. A pre-tender estimate should also be prepared.

For more information, contact:

Leigh Robinson

Director

Taylor Robinson

234 Railway Parade

West Leederville, Western Australia 6015

Australia

E-mail: Irobinson@tayrob.com.au

www.taylorrobinson.com.au 


\section{ORGANISATION FOR ECONOMIC CO-OPERATION AND DEVELOPMENT}

The OECD is a unique forum where the governments of 30 democracies work together to address the economic, social and environmental challenges of globalisation. The OECD is also at the forefront of efforts to understand and to help governments respond to new developments and concerns, such as corporate governance, the information economy and the challenges of an ageing population. The Organisation provides a setting where governments can compare policy experiences, seek answers to common problems, identify good practice and work to co-ordinate domestic and international policies.

The OECD member countries are: Australia, Austria, Belgium, Canada, the Czech Republic, Denmark, Finland, France, Germany, Greece, Hungary, Iceland, Ireland, Italy, Japan, Korea, Luxembourg, Mexico, the Netherlands, New Zealand, Norway, Poland, Portugal, the Slovak Republic, Spain, Sweden, Switzerland, Turkey, the United Kingdom and the United States. The Commission of the European Communities takes part in the work of the OECD.

OECD Publishing disseminates widely the results of the Organisation's statistics gathering and research on economic, social and environmental issues, as well as the conventions, guidelines and standards agreed by its members.

This work is published on the responsibility of the Secretary-General of the OECD. The opinions expressed and arguments employed herein do not necessarily reflect the official views of the Organisation or of the governments of its member countries.

You can copy, download or print OECD content for your own use, and you can include excerpts from OECD publications, databases and multimedia products in your own documents, presentations, blogs, websites and teaching materials, provided that suitable acknowledgment of OECD as source and copyright owner is given. All requests for public or commercial use and translation rights should be submitted to rights@oecd.org. Requests for permission to photocopy portions of this material for public or commercial use shall be addressed directly to the Copyright Clearance Center (CCC) at info@copyright.com or the Centre français d'exploitation du droit de copie (CFC) at contact@cfcopies.com. 